\title{
FREQUENCY OF PROSTATE CANCER AMONG THE PROSTATIC TISSUE SAMPLES- COLLECTED FROM DIFFERENT TERTIARY LEVEL HOSPITAL IN DHAKA CITY
}

\author{
MOHAMMAD MUKHLESUR RAHMAN ${ }^{1}$, MUHAMMAD MAHMUD ALAM ${ }^{2}$, MOHAMMAD OHIDUZZAMAN \\ KHAN $^{3}$, MOHAMMAD REZAUL KARIM ${ }^{4}$, MD. SAJID HASAN 5
}

\begin{abstract}
Background: Prostate cancer is the development of cancer in the prostate, a gland in the male reproductive system. The cancer cells may spread from the prostate to other area of the body, particularly the bones and lymph nodes. It may initially cause no symptoms. $A$ disease known as benign prostatic hyperplasiamay produce similar symptoms.

Objective: To identify the frequency of prostate cancer in prostatic tissue submitted for histopathological examination in selected hospital of Dhaka City.

Method: This analytical observational study consists of review of 3914 histopathological reports of prostatic specimen examined in 13 selected tertiary level hospitals in Dhaka city. This study was carried out from January 2007 to December 2009 (three years). All data were compiled, analyzed and appropriate statistical tests were done to make inference.

Results: During the study period, among the 2914 histopathological specimen of prostatic tissue, 637(about 16\%) cases were diagnosed as prostate cancer (including PIN), 3221 (about $82 \%$ ) cases were benign prostatic hyperplasia, $53(1.35 \%)$ were chronic prostatitis and the remaining 3 cases were other rare disease e.g. lipid storage disease etc. Among the prostate cancer, most common was prostatic adenocarcinoma (about 95\%); about $3 \%$ was Prostatic Intraepithelial Neoplasia (PIN), 1\% squamous cell carcinoma arid I \% are primary Transtiona1 cell carcinoma (TCC). Most of the patients diagnosed with prostate cancers are of advanced age - between 70 to 80 years (53.46\%), and the second peak age is $60-70$ years (34.57\%). Of the prostate cancer cases $8.78 \%$ were well differentiated, $34.84 \%$ were moderately differentiated and $64.36 \%$ were poorly differentiated. The ratio between benign and malignant prostatic disease was about 5:1. Though all the prostatic diseases are common in elderly people, benign prostatic disease occurs more commonly: in younger patients than the prostate cancer.

Conclusion: From this study it is evident that the burden of prostate cancer is still low in our context. But the disease seems to be increasing in recent years mainly due to increasing number of aged population. So in near future, the burden of the disease will be increasing throughout the world including our country. Prostate cancer is a slow growing tumor. It has a very sensitive tumor marker (PSA) also. Early diagnosis and proper management certainly improves the prognosis of the disease. There is a screening program for early diagnosis of the disease though it is relatively a costly program. Screening should be considered in persons who have a strong family history of prostate cancer. Every urologist, health policy makers should be aware of the burden of the disease and appropriate planning, necessary manpower \& skill development, resource allocation should be made to combat the situation efficiently.
\end{abstract}

Bangladesh J. Urol. 2018; 21(2): 88-92

1. Assistant Professor, Dept. of Urology, Syed Nazrul Islam Medical College, Kishoregonj.

2. Resident Surgeon, Mugda Medical College \& Hospita, Dhaka

3. Assistant Professor, Dept. of Urology, Faridpur Medical College, Faridpur.

4. Assistant Professor, Dept. of Urology, Patuakhali Medical College, Patuakhali.

5. Chairman, Dept. of Urology, Bangabandhu Sheikh Mujib Medical University, Dhaka

Address of correspondence : Dr. Mohammad Mukhlesur Rahman, Assistant Professor, Dept. of Urology, Syed Nazrul Islam Medical College, Kishoregonj. Mobile- 01712501032, E-mail:drsajaluro@gmail.com

Received: 9 August 2017

Accepted: 05 March 2018 


\section{Introduction}

The prostate gland is an important organ of male reproductive system which is commonly affected with benign and malignant neoplasm. Benign neoplasm is the most common pathology of the prostate gland and is commonly known as Benign Prostatic Hyperplasia (BPH). Most common (about 95\%) of the malignant neoplasm of the prostate gland arises from the glandular epithelium (adenocarcinoma) and commonly known as Carcinoma of Prostate (CaP). Some other varieties of malignant tumor also occur but they are very rare. ${ }^{1}$

Globally the prostate cancer is much prevalent. It is the second most common frequently diagnosed cancer among mend and the sixth leading cause of cancer death in men worldwide. From the available global statistics in 2007, and estimated 782000 new cases were diagnosed and 254000 patients died of carcinoma prostate. ${ }^{1}$ The probability of developing prostate cancer in men under the age of 40 years is 1 in 10,000:1 in 103 for men of $40-59$ years and 1 in 8 for men between 60-79 years of age. ${ }^{2}$

The number of patients with carcinoma prostate is increasing and according to the rates from 2003 to 2005 , it has been estimated that $15.78 \%$, or 1 in every 15 men will be diagnosed with prostrate cancer at some point during his lifetime. ${ }^{3}$

The mortality rate for prostate cancer has been decreasing in many developed country like the United States, United Kingdom, Canada in recent years. The has been attributed to early detection and improved treatment of the disease. In contrary, prostate cancer mortality is increasing in some Asian Countries Like Japan, Singapore etc. The cause of this is attributed to increased consumption of animal fat, obesity and physical inactivity. ${ }^{4}$

Prostate cancer is not uncommon in our country though it is generally assumed that the prevalence is low in our country. But unfortunately there is no reliable data on the incidence or prevalence of the disease yet today. A study on the prevalence of prostate cancer will be a milestone work in this field and will be much helpful for the urologists, researchers, health policy makers of the country.

The proposed study is an observational study of three years in which recorded data on prostatic disease (histopahological diagnosis) from renowned hospitals and clinics of Dhaka City was collected to see the frequency of Prostate cancer and other prostatic disease. Bangladesh is a small country about 1,44.000 $\mathrm{sq} \mathrm{km}$ with a vast population of more than 150 millions. Dhaka city, is the largest city of the country and majority of the modern treatment facilities including urological treatment is centralized to Dhaka. So, it can be assumed logically that a major portion of the prostate cancer cases from different corners of the country are diagnosed and managed in Dhaka City. As a result, data from the renowned public and private hospitals and urological centers of Dhaka city will cover majority of the cases of prostate cancer in the country. This study will reflects a major portion of the prostate cancer cases in the country.

\section{Materials and Methods}

It is hospital or institution based cross sectional descriptive observational study carried out Department of following tertiary level hospital and clinics of Dhaka city: Bangabandhu Sheikh Mujib Medical University (BSMMU), Dhaka Medical College Hospital (DMCH), Sir Salimullah Medical College \& Mitford Hospital (SSMCH), National Institute of Kidney Disease and Urology (NIKDU), National Institute of Cancer Research (NICRH), BIRDEM Hospital, Bangladesh Medical College Hospital $(\mathrm{BMCH})$, Dhaka, Comfort Nursing Home, Barakah Kidney Hospital \& Research Institute Ltd (BKHRL), Islami Bank Hospital, The Laboratory, United Hospital, Lad Aid Hospital, Dhaka from 2007 to 2009. Specimen of prostatic tissue that was sent for histopathological examination. A data collection sheet was used for the collection of data. Data were analyzed using SPSS programme.

\section{Results}

Table-I

Histopathological diagnosis of prostatic tissue simple in different hospitals and institutions ( $n=3914)$.

\begin{tabular}{lcccccc}
\hline Institution & $\begin{array}{c}\text { Prostate } \\
\text { Cancer }\end{array}$ & PIN & BPH & $\begin{array}{c}\text { Chronic } \\
\text { Prostatitis }\end{array}$ & Other Total \\
\hline BSMMU & 134 & 8 & 413 & 31 & 1 & 587 \\
DMCH & 71 & 6 & 352 & 12 & 1 & 442 \\
SSMCH & 13 & & 148 & & 161 \\
NIKDU & 26 & 2 & 230 & 4 & 262 \\
BIRDEM & 21 & & 204 & & 225 \\
NICRH & 0 & & 5 & & 5 \\
BMCH & 87 & & 396 & 2 & 485 \\
Comfort NH & 82 & & 256 & & 338 \\
BKHRL & 70 & 3 & 478 & 3 & 1 & 555 \\
The Laboratory & 22 & & 144 & 1 & 167 \\
IBH & 68 & & 361 & & 429 \\
United Hosp & 5 & & 62 & & 67 \\
Lab Aid & 19 & & 172 & & 3914 \\
\hline Total & 618 & 19 & 3221 & 53 & 3 & 391 \\
\hline
\end{tabular}


Table-II

Distribution of all patients by diagnosis $(n=3914)$

\begin{tabular}{lcc}
\hline Diagnosis & No. of cases & Percentage $(\%)$ \\
\hline Adenocarcinoma & 606 & 15.48 \\
Squamous cell carcinoma & 7 & 0.18 \\
TCC & 5 & 0.14 \\
PIN & 19 & 0.48 \\
BPH & 3221 & 82.29 \\
Chr. Prostatitis & 53 & 1.35 \\
Other & 3 & 0.08 \\
\hline Total & 3914 & $100 \%$ \\
\hline
\end{tabular}

Table-III

Distribution of patients by type of prostate cancer $(n=637)$

\begin{tabular}{lcc}
\hline Diagnosis & No. of cases & Percentage (\%) \\
\hline Adenocarcinoma & 606 & 95.13 \\
Squamous cell carcinoma & 7 & 1.10 \\
TCC & 5 & 0.79 \\
PIN & 19 & 2.98 \\
\hline Total & 637 & $100 \%$ \\
\hline
\end{tabular}

Table-IV

Distribution of prostate cancer patients by age $(n=637)$

\begin{tabular}{lccccc}
\hline Age group(yrs) & Adeno ca & Sq. cell ca & TCC & PIN & Total \\
\hline $41-50$ & $18(2.98)$ & $1(14.29 \%)$ & & $4(21.05 \%)$ & $23(3.61 \%)$ \\
$51-60$ & $67(11.06 \%)$ & $4(57.14 \%)$ & & $5(26.32 \%)$ & $76(11.93 \%)$ \\
$61-70$ & $106(17.49 \%)$ & $2(28.58 \%)$ & $2(40 \%)$ & $5(26.32 \%)$ & $115(18.05 \%)$ \\
$71-80$ & $301(49.67 \%)$ & & $3(60 \%)$ & $4(21.05 \%)$ & $308(48.35 \%)$ \\
$81-90$ & $102(16.83 \%)$ & & & $1(5.26 \%)$ & $103(16.17 \%)$ \\
$>90$ & $12(1.98 \%)$ & & & & $12(1.88 \%)$ \\
\hline Total & $606(100 \%)$ & $7(100 \%)$ & $5(100 \%)$ & $19(100 \%)$ & $637(100 \%)$ \\
\hline
\end{tabular}

Table-V

Comparison between benign prostatic disease and prostate cancer in relation to age

\begin{tabular}{lccc}
\hline & $\leq 60$ years & $>60$ years & P value \\
\hline Benign (\%) & 85.96 & 71.05 & $<0.05$ \\
Malignant (\%) & 14.04 & 28.95 & \\
\hline
\end{tabular}

\section{Table-VI}

Grading of prostate adenocarcinoma according to Glasson grading system $(n=606)$

\begin{tabular}{lcc}
\hline Gleason grade \& Score & \multicolumn{2}{c}{ No. of Percent } \\
& cases & $(\%)$ \\
\hline Well differentiated (GS2-4) & 62 & 10.23 \\
Moderately differentiated (GS 5-6,7*) & 211 & 34.82 \\
Poorly differentiated (GS 7 $\left.7^{* *}, 8-10\right)$ & 321 & 52.97 \\
Note done & 12 & 1.98 \\
\hline Total & 606 & $100 \%$ \\
\hline
\end{tabular}

Table-VII

Grading of adenocarcinoma according to Glasson grading system $(n=606)$

\begin{tabular}{lc}
\hline Gleason grade \& Score & Percentage (\%) \\
\hline Well differentiated (GS2-4) & $10 \%$ \\
Moderately differentiated (GS 5-6, $7^{*}$ ) & $35 \%$ \\
Poorly differentiated (GS 7**, 8-10) & $53 \%$ \\
Note done & $2 \%$ \\
\hline Total & $100 \%$ \\
\hline
\end{tabular}

\section{Discussion}

Prostate cancer is the second most common cancer among men and the sixth leading cause of cancer death in men worldwide. It has been estimated that $15.78 \%$, or I in every 15 men, will be diagnosed with prostate cancer at some point during his lifetime. ${ }^{3}$ The chance of prostate cancer increases with age. But there is marked variation in the incidence and prevalence of the disease among the countries and in different ethnicity. The highest incidence of the disease is in the industrialized nations. In the USA about 2,20,000 new cases of prostate cancer were diagnosed in 2005. In 
UK, there were 35,515 new cases of prostate cancer diagnosed in 2006. $5,6,7,8$ This indicates the huge burden of the disease in these countries. In our country, most of the urological cancer cases are diagnosed and managed in the capital city of Dhaka. So it can be assumed logically that the number of cases presented in this series is the lion's share of the total diagnosed cases of the country. In Asian countries including our country, the prevalence of prostate cancer is much low in comparison to western world. But it has been shown in some study that, in recent years, the incidence of prostate cancer is increasing in many Asian countries including our country. This increase is mainly due to increasing number of aging people, westernization of diet habit and improved imaging \&other diagnostic facilities, But unfortunately till today, there is no available data on prevalence of prostate cancer in our country. The objective of my thesis is to find out the frequency of prostate cancer \& other prostatic disease in the histopathological tissue specimen of prostate collected from selected centers in Dhaka city so that from this picture one can predict the overall trend of the prostatic disease in our country.

In the present series, 3914 number of histopathological reports of prostatic tissue specimen collected from selected 13 tertiary level hospitals diagnostic centers in Dhaka city were reviewed. Among them, 1457 cases were from the public hospitals including the BSMMU. The remaining 2457 were from the private hospitals. Out of 637 prostate cancer cases (including PIN), 260 were from the public hospitals and the remaining 377 were in private hospitals. Among the public hospitals, highest number of prostate cancer cases (142) was diagnosed in the BSMMU.

Among 3914 cases included in the study, 637 (16.27\%) were diagnosed as prostate cancer (including the PIN) and the remaining 3277 (83.73\%) were benign disease. This reflects that among the histopathologically diagnosed cases of prostatic disease, about one fifth is prostate cancer. Most common type of prostate cancer was adenocarcinoma (about 95\%); about 3\% are Prostatic Intraepithelial Neoplasia (PIN), 1\% squamous cell carcinoma and $1 \%$ are Transitional Cell Carcinoma (TCC). There was statistically no difference between the percentage of adenocarcinoma in the sample data \& the population data as found in most studies. It may be noted here that most of the TCC of prostatic urethra occur simultaneously with bladder ICC and is usually reported as bladder cancer. This observed result is consistent with internationally accepted type of prostate cancer.
From 3277 number of benign cases, 3221 (about $98.29 \%$ ) were BPH, 53 (I .62\%) were chronic prostatitis (almost at arc associated with BPH) and the remaining 3 were other disease like lipid storage disease.

The strongest known risk factor for prostate cancer is advancing age. The occurrence of prostate cancer increases with increasing age. The risk of Prostate cancer is very less in men under the age 50 years and there after the risk increases with increasing age. The older the men, the higher the risk and in some post mortem results approximately $80 \%$ of men by the age 80 years have found to have cancer cells in their prostate.

In the present series, most of the prostate cancer patients were between the ages 71-80 years (about $49 \%$ ), and mean age was 72.72 years. This result is consistent with the results of most other studies. Benign prostatic disease is comparatively more common in younger age group than the prostate cancer. En less than 60 years age group, benign prostatic disease is $28.95 \mathrm{~W}$ \& prostate cancer is $14.04 \%$. In more than 60 years age group, benign disease is $71.05 \%$ \& cancer is $85.96 \%$. Chi square test proves that there is significant higher rate of prostate cancer in older age group.

Grade of the disease is related with progression of the disease and ultimately prognosis. Gleason grading system is the most widely practiced grading system for prostate cancer. The Gleason system is based on the glandular pattern of the tumor as identified at relatively low magnification. The risk of progression is low in those with Gleason grades 2-6, but increases significantly for those with Gleason grades 7 through 10.

In the present series, most of the cases of prostate cancer were poorly differentiated (about $53 \%$ ) which carries a higher chance of disease progression and a poorer prognosis. About 35\% cases are moderately differentiated \& only about $10 \%$ are well differentiated cancer. In about $2 \%$ cases Gleason grading were not done. This finding agreement with the study of Balkrishna. ${ }^{9}$

In the present series, only 637 cases of prostate cancer were diagnosed in three years period from 2007 to 2009 in selected 13 urological centers in Dhaka city. From the results of the series, it is clear that in a country of more than 150 millions of population, the number of prostate cancer cases are very low. However, it can be 
noted here that a large number of prostate cancer cases are not diagnosed or reported properly due to lack of improved treatment faci1ities and consciousness of the patients. Another significant factor may as the prostate cancer usually occur in the elderly people, many of such patients die due to other medical cause e.g. cardiac or respiratory diseases before prostate cancer become clinically evident. So the data revealed in this series may be only the partial picture of the actual condition.

\section{Conclusion}

My study shows that among the prostatic disease diagnosed from histopathological specimen, prostate cancer was 637(about 16\%).Most prostatic cancer was adenocarcinoma. Most cancer cases occur in elderly population. Total number of cases diagnosed in this three years period is not very large. So apparently it seems that the disease burden is not so huge in our country. But the disease is increasing in recent years mainly due to increasing number of aged population. So, in near future the burden of the disease will be increased throughout the world and also in our country. Prostate cancer is a slow growing tumor. The disease has a well defined marker also. Early diagnosis and proper management certainly improves the prognosis of the disease. There is a screening program for early diagnosis of the disease but it is relatively a costly program. So every urologist, health policy makers should be aware of the burden of the disease and appropriate planning, necessary manpower \& skill development, resource allocation should be done to combat the situation efficiently.

\section{References}

1. Jamal A, Sigel R, Ward E. Cancer statistics 2008. CA Cancer J Clinic 2008;58:71-96.

2. Thango, Emil A, McAinich JW. Carcinoma of the prostate, incidence \& epidemiology: Smith's General Urology, McGraw Hill, NY 2004;'355-356.

3. Ries L, Melbert D, Draphco M. SEER cancer statistics review (based on November 2007 SEER data submission, posted to the SEER weibsite 2008).

4. Carcia M, Jemal A, Ward E. Global cancer facts and figures 2007, Available at http:/www. cancer.org/downloads/STT.

5. Quinn M, Babb P. Patterns and trends in prostate cancer incidence, survival, prevalence and mortality. Part I: International comparisons. Br. J Urol Int 2002;90:162-173.

6. Salam M. Staging of prostate cancer' in Principal and Practice of Urology, MAS publications, Dhaka 2002;668-671.

7. Theodorescu D. Prostate cancer, clinical oncology. In: Schwah M. (eds). Encyclopedic reference of cancer. Springer Verlag, NY $2001 ; 720$.

8. Thompson I, Thrasher JB, Aus G. Guideline for the management of clinically localized prostate cancer. Update J Urol 2007;177:2106-2131.

9. Balkrishna YB. Trends in the prostate cancer incidence in India, Asian Pacific Journal of Cancer Prevention 2008;9(1):141-4. 